\title{
Descrição da morfologia oral interna, ontogenia e redescrição do girino de Bokermannohyla circumdata (Cope, 1870) (Amphibia: Anura: Hylidae) \\ Description of oral cavity morphology, development and redescription of the tadpole of Bokermannohyla circumdata (Cope, 1870) (Amphibia: Anura: Hylidae)
}

\author{
Marcelle Mantoanelli Mongin', Ana Maria Paulino Telles de Carvalho-e-Silval \\ 'Universidade Federal do Estado do Rio de Janeiro. Rio de Janeiro, Rio de Janeiro, Brasil
}

Resumo: Redescreve-se o girino de Bokermannohyla circumdata, do Parque Nacional da Serra dos Órgãos, Teresópolis, Rio de Janeiro, acrescentando dados sobre desova, desenvolvimento, variação na fórmula de dentículos labiais e morfologia oral interna.

Palavras-chave: Mata Atlântica. Desova. Recém-metamorfoseado. Brasil. Parque Nacional da Serra dos Órgãos.

\begin{abstract}
Following is a redescription of the tadpole of Bokermannohyla circumdata from Serra dos Órgãos National Park, Teresópolis, Rio de Janeiro, Brazil, with data on spawning, development, variation in labial teeth formula and oral cavity morphology.
\end{abstract}

Keywords: Atlantic Forest. Spawning. Metamorphosed froglet. Brazil. Serra dos Órgãos National Park.

MONGIN, M. M. \& A. M. P. T. CARVALHO-E-SILVA, 2013. Descrição da morfologia oral interna, ontogenia e redescrição do girino de Bokermannohyla circumdata (Cope, 1870) (Amphibia: Anura: Hylidae). Boletim do Museu Paraense Emílio Goeldi. Ciências Naturais 8(2): 133-152.

Autor para correspondência: Marcelle Mantoanelli Mongin. Universidade Federal do Estado do Rio de Janeiro. Departamento de Zoologia. Avenida Pasteur, 485. Bloco 3, IBIO. Sala 402. Urca. Rio de Janeiro, RJ, Brasil. CEP 20290-240 (marcellemongin@yahoo.com.br).

Recebido em 21/08/2012

Aprovado em 20/07/2013

Responsabilidade editorial: Marinus Hoogmoed

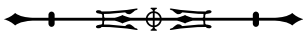




\section{INTRODUÇÃO}

gênero Bokermannohyla, cuja monofilia é baseada principalmente em dados moleculares, foi proposto por Faivovich et al. (2005). Atualmente, possui trinta espécies, encontradas entre a Mata Atlântica e o Cerrado brasileiro, distribuídas em quatro grupos fenéticos: $B$. circumdata (Cope, 1870), B. pseudopseudis (Miranda-Ribeiro, 1937), B. martinsi (Bokermann, 1964) e B. claresignata (Lutz \& Lutz, 1939) (Frost, 2011; Carvalho et al., 2012).

O grupo de Bokermannohyla circumdata distribui-se em ambientes associados a água corrente dentro da Mata Atlântica e do Cerrado, principalmente nos complexos da Serra do Mar e da Mantiqueira (Napoli, 2005; Napoli \& Pimenta, 2009). As espécies desse grupo caracterizam-se por possuir dorso marrom, região posterior das coxas com faixas transversais escuras e, nos machos, pré-pólex não bífido e antebraços hipertrofiados (Heyer, 1985; Napoli \& Juncá, 2006; Napoli \& Pimenta, 2009). Além disso, o grupo também é definido por possuir 52 transformações mitocondriais, de proteínas nucleares e de genes ribossomais (Faivovich et al., 2005).

Bokermannohyla circumdata ocorre na Serra do Mar, em montanhas do Espírito Santo, Minas Gerais, Rio de Janeiro, São Paulo e Santa Catarina (Frost, 2011). Pombal Jr. \& Haddad (2007) definem modos reprodutivos em anuros, e $B$. circumdata enquadra-se no modo 4, no qual os ovos são depositados em piscinas naturais ou construídas, permanecendo até os estágios larvais iniciais; após inundação, os girinos exotróficos passam para os corpos d'água lênticos ou lóticos. Bokermann (1966) designa a localidade-tipo para B. circumdata como sendo Rio de Janeiro, Guanabara, até então conhecida apenas como Brasil.

Das dezenove espécies do grupo, dez possuem seus girinos descritos. As espécies cujos girinos foram descritos juntamente com a descrição original são: $B$. carvalhoi (Peixoto, 1981), B. feioi (Napoli \& Caramaschi, 2004), B. luctuosa (Pombal Jr. \& Haddad, 1993), B. nanuzae (Bokermann \& Sazima, 1973) e B. sazimai (Cardoso \& Andrade, 1982). As espécies cujos girinos foram descritos posteriormente são: B. capra Napoli \& Pimenta, 2009 por Mercês et al. (2012), B. circumdata por Peixoto (1981), B. gouveai (Peixoto \& Cruz, 1992) por Costa et al. (2010), B. hylax (Heyer, 1985) por Bertoluci et al. (2003) e B. ibitipoca (Caramaschi \& Feio, 1990) por Magalhães et al. (2012).

$\mathrm{Na}$ descrição original de $B$. carvalhoi, seu girino foi descrito em comparação, de forma sucinta, com o girino de $B$. circumdata, uma vez que as duas espécies ocorrem juntas na localidade de Teresópolis, estado do Rio de Janeiro (Peixoto, 1981).

A morfologia oral interna de duas espécies do grupo, B. luctuosa e B. nanuzae, foi descrita por D'Heursel \& Haddad (2007).

O objetivo deste trabalho é redescrever o girino de Bokermannohyla circumdata e descrever seu desenvolvimento, acrescentando dados sobre a sua desova e morfologia oral interna.

\section{MATERIAL E MÉTODOS}

Este estudo foi realizado na sede de Teresópolis (22 $27^{\circ}$ 24" S e 420 59' 41" O), do Parque Nacional da Serra dos Órgãos (PARNASO), localizado na região Sudeste do Brasil, estado do Rio de Janeiro. Foram realizadas 20 excursões ao PARNASO, de julho de 2006 a setembro de 2010. Foram analisados 126 girinos de $B$. circumdata, parte coletada na altitude aproximada de $1.100 \mathrm{~m}$ acima do nível do mar, nos pequenos afluentes dos rios Paquequer e Beija-Flor. Também foi utilizado material dessa mesma localidade tombado na Coleção do Laboratório de Biossistemática de Anfíbios, da Universidade Federal do Estado do Rio de Janeiro, optando-se sempre por girinos não criados. A identificação dos girinos foi baseada em Peixoto (1981). Os estágios de desenvolvimento foram definidos segundo Gosner (1960).

A contagem dos ovos foi feita após a coleta, em uma bandeja. Parte deles foi fixada logo após a coleta e parte foi levada ao laboratório, para observação dos estágios iniciais de desenvolvimento (até o estágio 25). Dez ovos foram medidos com paquímetro digital antes e depois da fixação, considerando a cápsula gelatinosa. 
Alguns girinos em estágios avançados, posteriores ao 42 , foram criados em aquários com água trazida do ambiente até a metamorfose, para possibilitar a identificação do recém-metamorfoseado.

Para o estudo do desenvolvimento, os girinos foram fixados em formol 5\%, após a identificação prévia dos estágios em campo. Dessa maneira, evitou-se trabalhar com girinos criados por longos períodos, o que poderia gerar alterações na morfologia. Todos foram tombados na coleção referida acima.

Para melhor visualização da região oral, alguns girinos foram fixados segundo a técnica de Carvalho-e-Silva \& Carvalho-e-Silva (1994). A fórmula de dentículos labiais do girino foi determinada utilizando-se McDiarmid \& Altig (1999). Foi utilizado o Teste de Friedman para analisar a influência do estágio de desenvolvimento sobre a fórmula de dentículos labiais no girino.

Para a descrição da morfologia oral interna, utilizaram-se oito girinos nos estágios $26(n=4)$ e $36(n=4)$, enquanto a nomenclatura seguiu Wassersug (1976), D'Heursel \& Haddad (2007) e Miranda \& Ferreira (2009). Na preparação do material, foi utilizada tesoura de $11 \mathrm{~cm}$ para microcirurgia, microscópio estereoscópico e solução de azul de metileno 1\%, diluída em água na proporção 1:100 ml. A determinação das cores dos indivíduos baseou-se no catálogo de cores para naturalistas de Smithe (1975). Os exemplares foram medidos segundo McDiarmid \& Altig (1999), utilizando-se paquímetro digital: comprimento total (CT), comprimento do corpo (CCOR), comprimento da cauda (CCAU), largura do corpo (LCOR), altura do corpo (ACOR), altura máxima da cauda (ACAU), distância entre narina e focinho (NF), distância entre espiráculo e focinho(EF), distância entre olho e focinho (OF), distância entre os olhos (OO), distância entre olho e narina $(\mathrm{ON})$, distância entre as narinas (NN), largura da boca ( $\mathrm{LBOC}$ ), diâmetro do olho (DOL) e diâmetro da narina (DN).

Algumas proporções dos girinos de $B$. circumdata foram calculadas e utilizadas na discussão, ao serem comparadas com outras espécies do grupo. Em B. capra, B. hylax, B. ibitipoca, pela ausência de proporções relevantes para diferenciação, as proporções foram calculadas a partir dos valores brutos, provenientes da literatura (Mercês et al., 2012; Bertoluci et al., 2003; Magalhães et al., 2012), com cálculo simples de média e desvio padrão.

O material analisado está tombado na coleção de anfíbios do Laboratório de Biossistemática de Anfíbios da Universidade Federal do Estado do Rio de Janeiro: UNIRIO $924,1149,1243,1255,1461,1622,1650,1718,1760,1790$, $2346,2376,2426,2427,2438,2517,2620,2627,2650$, $2653,2669,2671,2703,2705,2706,2707,2829,2889$, $2890,2976,2977,2979,3047,3090,3195,3196,3226$, 3364, 3587, 3743, 4029, 4071, 4074, 4084.

\section{RESULTADOS}

O girino de Bokermannohyla circumdata é exotrófico e lótico-bentônico, vivendo escondido sob folhas ou na argila no fundo de riachos, deslocando-se do ambiente da desova, na margem desses pequenos afluentes, após inundação do local. Foram observados girinos em diversos estágios, estando os mais novos aproximadamente no estágio 28, locomovendo-se sobre a lama de forma serpentiforme quando perturbados, podendo deslocar-se rapidamente fora da água.

Uma desova foi encontrada em uma cavidade construída, coberta por folhas caídas de bambu, muito próxima a um corpo de água, onde o solo era extremamente úmido, em local não abrigado do sol, com 1.176 ovos. A cavidade no solo media $207 \mathrm{~mm}$ por $145 \mathrm{~mm}$ de diâmetro e $76 \mathrm{~mm}$ de profundidade (Figura 1)). Os ovos eram esféricos, com diâmetro médio de 8,8 \pm 0,7 mm em vida e 6,3 \pm $1,2 \mathrm{~mm}$ fixados (para ambos $\mathrm{n}=10$ ). Apresentavam polo animal escuro e polo vegetal claro na mesma proporção. Os embriões localizados dentro dos ovos na superfície da desova estavam em estágios mais avançados de desenvolvimento (estágio 23), e os encontrados no centro, em estágios anteriores, aproximadamente entre os estágios 17 e 22 (Figura 1K). Observou-se que, algumas horas após a contagem dos ovos, muitos já haviam eclodido no estágio 23. Alguns girinos no estágio 25 foram fixados 4 horas após a coleta da desova.

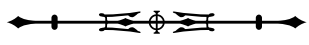


REDESCRIÇÃO DO GIRINO (ESTÁGIO 36-37 $(\mathrm{N}=10)$; FIGURAS 1D-1I, 2A; TABELAS 1-2)

Corpo robusto, oval em vista dorsal, com focinho arredondado; CCOR 30\% do CT; sistema de linha lateral evidente; olhos dorso-laterais, com distância ente si equivalendo a 37\% do CCOR; narinas elípticas, com projeção no seu bordo interno e distância entre si equivalendo a 18\% do CCOR, situadas mais próximas dos olhos do que do focinho; espiráculo sinistro, não colado ao corpo, com extremidade despigmentada; tubo anal com abertura destra; cauda com musculatura bem desenvolvida; nadadeira dorsal mais alta que ventral, iniciando-se na base da cauda; disco oral antero-ventral, de largura equivalendo a $37 \%$ da largura do corpo, margeado por uma fileira de papilas duplas (simples na porção anterior em alguns exemplares), interrompidas na porção anterior, e o lábio posterior desenvolvido, com reentrância nas margens; fórmula de dentículos labiais [2(2)/3(1); 2(2)/4(1)]; bico córneo desenvolvido e serrilhado; dentículos labiais espatulados com extremidade convexa e cabeça possuindo 8-10 cúspides bem marcadas.

DESENVOLVIMENTO DO GIRINO ( $N=126$, FIGURA 2A, TABELAS 1-3, FIGURAS 4-7)

O corpo do girino é $1 / 3$ (30\%) de seu comprimento total até o estágio 41 , aumentando para $40 \%$ no estágio 42 , $60 \%$ no estágio 43, 80\% no estágio 45 e 100\% no estágio 46, recém-metamorfoseado (Figura 4). O comprimento total dos girinos atinge o tamanho máximo no estágio 39, com 47,9 \pm 4,2 (41,9-53,7) mm (Tabela 2). No desenvolvimento do corpo, OO, DOL e ON aumentam constantemente, enquanto NN diminui e DN se mantém; os olhos se afastam, assim como a narina se aproxima do focinho (Figura 5). As distâncias OF, NF e LBOC aumentam nos estágios iniciais, mantendo-se constantes até o início da metamorfose, estágio 42, quando OF e NF diminuem e LBOC aumenta acentuadamente (Figura 6). A altura da cauda é maior que a altura do corpo no estágio 25 , e equivalente entre os estágios 26 e 36;
ACAU aumenta do estágio 37 ao 41 e diminui até não haver mais cauda no estágio 46, devido à sua absorção durante a metamorfose (Figura 7).

O girino no estágio 42 apresenta sistema de linha lateral, a cauda possui ainda nadadeiras dorsal e ventral bem marcadas e o limite posterior da boca terminando entre a narina e o olho. No estágio 43, ele não possui sistema de linha lateral na região do canto rostral, as nadadeiras começam a desaparecer e o limite posterior da boca ainda se encontra entre a narina e o olho. No estágio 44, já não existem mais as membranas das nadadeiras.

\section{MORFOLOGIA ORAL INTERNA (ESTÁGIO 36; FIGURA 3)}

Assoalho bucal: forma triangular com comprimento 1,3 vezes maior que a largura; cinco pares de papilas infralabiais presentes, bem discerníveis; o par mais interno, mais comprido que largo, de formato palmar, com nove projeções digitiformes distintas, providas de pequenas irregularidades nas extremidades; os quatro pares anteriores separados do par posterior, sendo o mais próximo do posterior de formato palmar com três projeções digitiformes; três pares anteriores longos sem ramificação; um par de papilas com formato alongado situado entre o par digitiforme de infralabiais e as papilas linguais; duas papilas linguais presentes, situadas no mesmo plano transverso, afiladas, longas e curvas; papilas linguais mais próximas das papilas infralabiais do que das papilas do assoalho; papilas da área do assoalho dispostas em formato de $U$, em toda margem lateral até o fundo; com 24 papilas de cada lado, delimitando a arena do assoalho, a maioria direcionada para o centro e diagonalmente para cima; papilas digitiformes, encurvadas, de superfície lisa e tamanhos distintos; seis papilas no fundo do assoalho, lateralmente às fileiras de papilas da área do assoalho; cerca de seis papilas das bolsas bucais presentes, digitiformes e curtas; grande número de pústulas na superfície da área do assoalho bucal, distribuídas uniformemente; velum ventral com margem ondulada. 


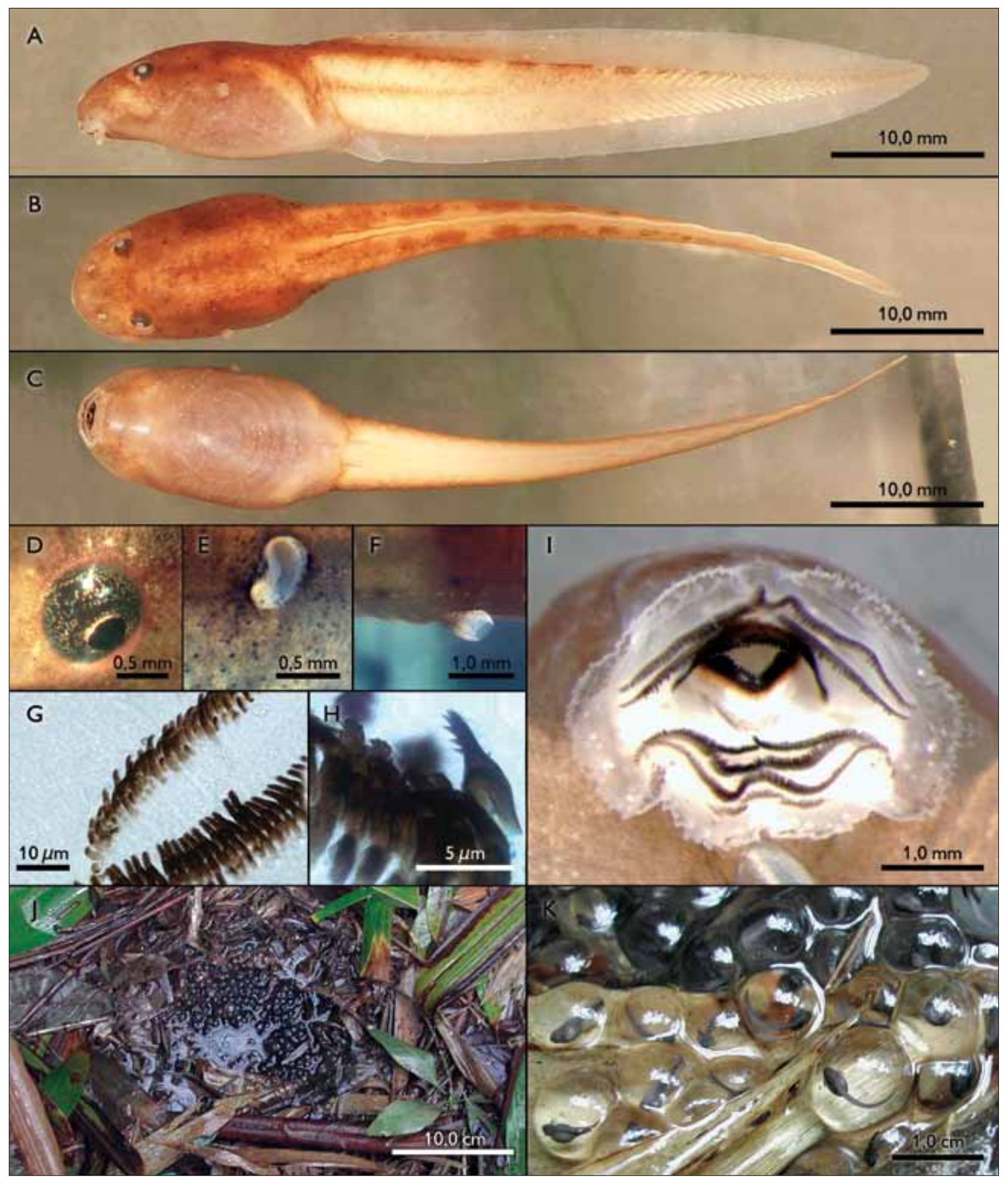

Figura 1. Girino de Bokermannohyla circumdata. Girino fixado no estágio 28 em vista lateral (A), dorsal (B) e ventral (C). Em detalhe: olho (D, em vida), narina (E), espiráculo (F), fileira de dentículos labiais $(\mathrm{G}, \mathrm{H})$ e disco oral com fórmula de dentículos labiais 2(2)/4(1) (I), desova no ambiente (J) e ovos acima da superfície da água com embriões no estágio 22/23 (K). 


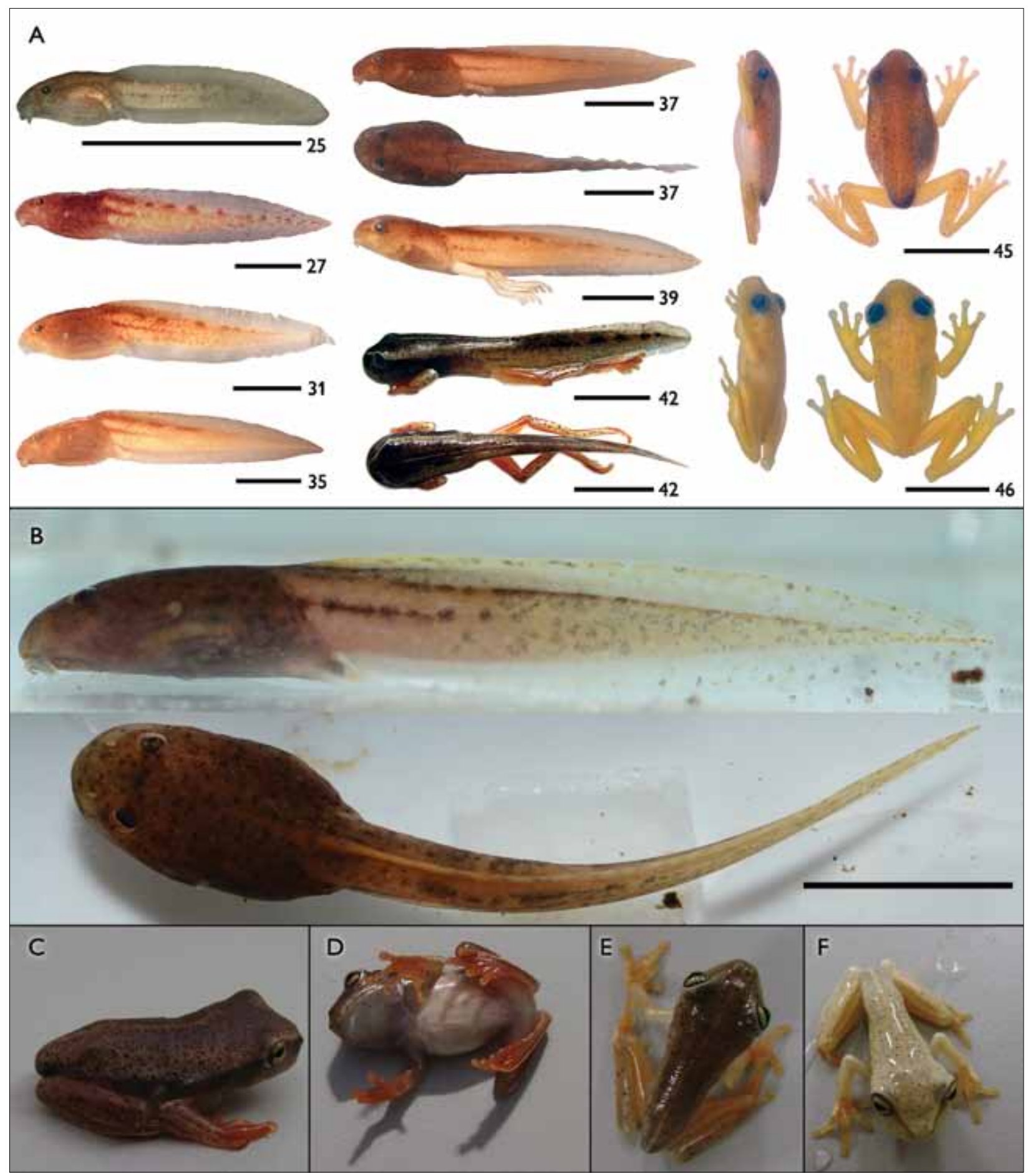

Figura 2. Girinos e recém-metamorfoseados de Bokermannohyla circumdata fixados nos estágios 25, 27, 31, 35 e 39 , em vista lateral, 37, 42 (fotografado logo após fixação), 45 e 46, em vista lateral e dorsal (A). Girino em vida no estágio 29, em vista lateral e dorsal (B). Recém-metamorfoseados em vida com coloração escura ( $C$ e D, mesmo indivíduo) e coloração mediana e clara (E e F, mesmo indivíduo). Todas as escalas com 1,0 cm. 


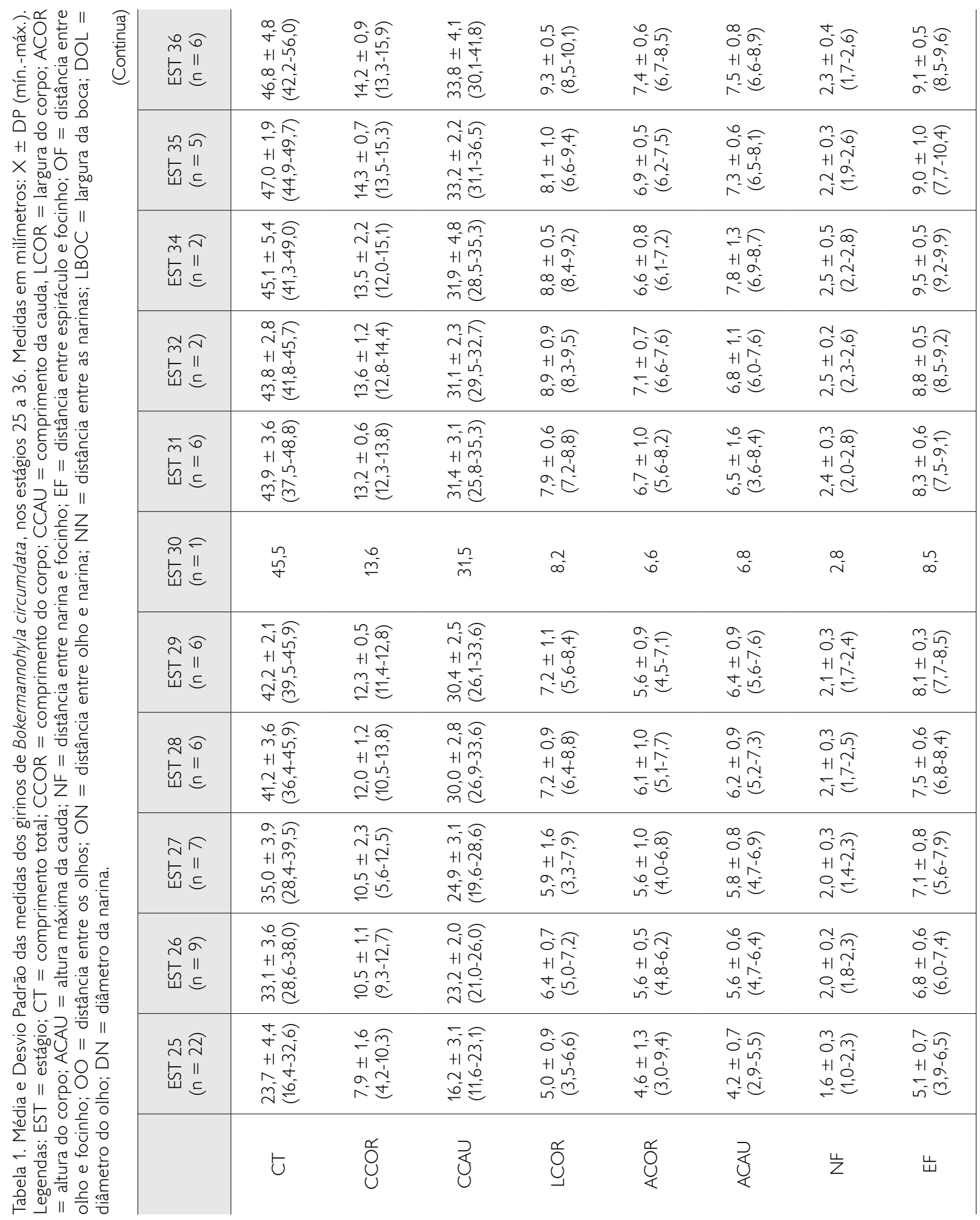




\begin{tabular}{|c|c|c|c|c|c|c|c|c|}
\hline 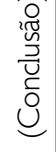 & 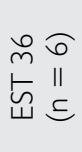 & 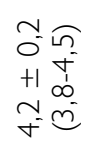 & 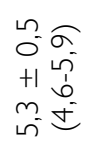 & 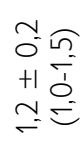 & 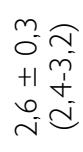 & $\begin{array}{l}n= \\
0-\tilde{m} \\
+1 \\
m \\
m \\
m \\
m \\
m\end{array}$ & 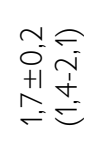 & $\begin{array}{l}-\overline{0} \\
0 \\
+10 \\
0 \\
0 \\
0 \\
0\end{array}$ \\
\hline & 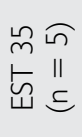 & 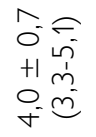 & 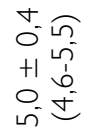 & 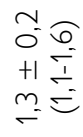 & $\begin{array}{l}m \\
0 \\
0 \\
+1 \\
+1 \\
0 \\
d \\
d \\
d\end{array}$ & 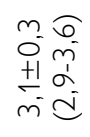 & 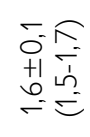 & $\begin{array}{ll}0 & - \\
0 & 0 \\
+1 & 0 \\
& 0 \\
0 & 0\end{array}$ \\
\hline & 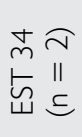 & 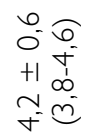 & $\begin{array}{l}0 \\
0 \\
0 \\
+1 \\
+1 \\
m \\
m \\
m^{-} \\
n^{-}\end{array}$ & 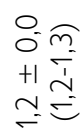 & 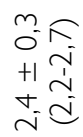 & 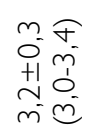 & 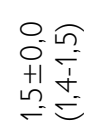 & $\begin{array}{l}=0 \\
=0 \\
+1 \\
+1 \\
\tilde{0} \\
0 \\
0\end{array}$ \\
\hline & 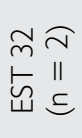 & $\begin{array}{l}\overline{0}= \\
+1 \bar{f} \\
+1 \\
\bar{f}=\end{array}$ & 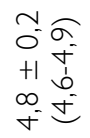 & 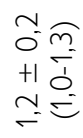 & 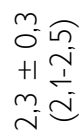 & $\begin{array}{l}\stackrel{\sim}{\sigma} \\
0 \\
+1 \\
+1 \\
m \\
m \\
m \\
m\end{array}$ & 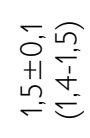 & 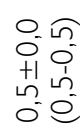 \\
\hline & 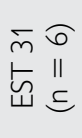 & 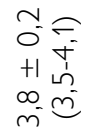 & 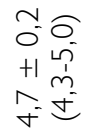 & 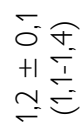 & 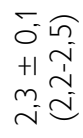 & 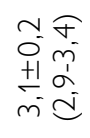 & 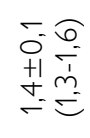 & 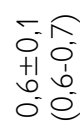 \\
\hline & 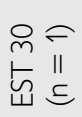 & $\stackrel{m}{\nabla}$ & $\bar{E}$ & $\stackrel{\simeq}{\cong}$ & $\stackrel{+}{i}$ & $m_{m}^{m}$ & $\stackrel{\nabla}{=}$ & $t_{0}^{+}$ \\
\hline & 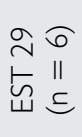 & 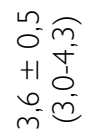 & 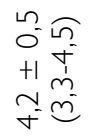 & $\begin{array}{l}\mathfrak{v} \approx \\
0= \\
+10 \\
=0 \\
=0\end{array}$ & 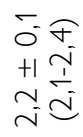 & 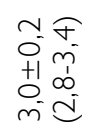 & 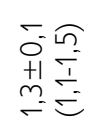 & $\begin{array}{l}-\infty \\
0 \\
+10 \\
+1 \\
0 \\
0 \\
0 \\
0\end{array}$ \\
\hline & 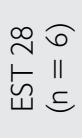 & 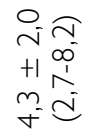 & $\begin{array}{l}\tilde{n} \\
\tilde{o}^{-} \\
+1 \\
+1 \\
\sigma^{-} \\
\tilde{m}^{-}\end{array}$ & 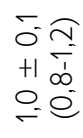 & 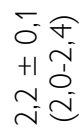 & $\begin{array}{l}m \\
m \\
0 \\
+1 \\
0 \\
0 \\
i \\
i \\
d\end{array}$ & 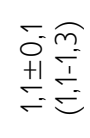 & 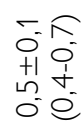 \\
\hline & 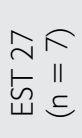 & 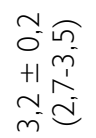 & 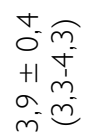 & 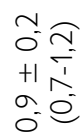 & 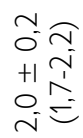 & 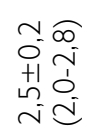 & 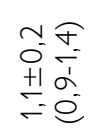 & 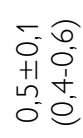 \\
\hline & 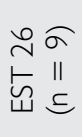 & 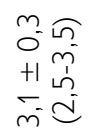 & $\begin{array}{l}+\vec{\sigma} \\
\stackrel{\sigma}{\sigma} \\
+1 \\
+1 \\
\dot{m}^{\prime} \\
m^{-}\end{array}$ & $\begin{array}{l}\overline{0}= \\
+1= \\
\infty \\
0-0 \\
0=0\end{array}$ & 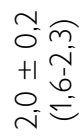 & $\begin{array}{l}m \\
0 \\
0 \\
+1 \\
0 \\
\sim \\
i \\
\sim\end{array}$ & 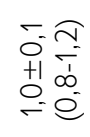 & 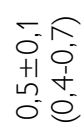 \\
\hline & 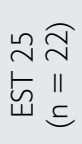 & 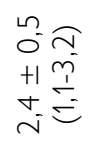 & 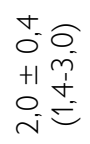 & 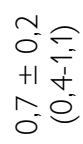 & 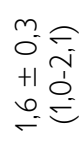 & 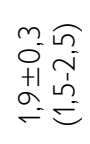 & $\begin{array}{l}n= \\
0= \\
+1 \\
t=- \\
0=\end{array}$ & 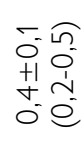 \\
\hline$\overline{0}$ & & 岁 & ○ & Ò & Z & \begin{tabular}{l}
$\cup$ \\
$O$ \\
\hdashline
\end{tabular} & $\begin{array}{l}\overrightarrow{0} \\
0\end{array}$ & Z \\
\hline
\end{tabular}




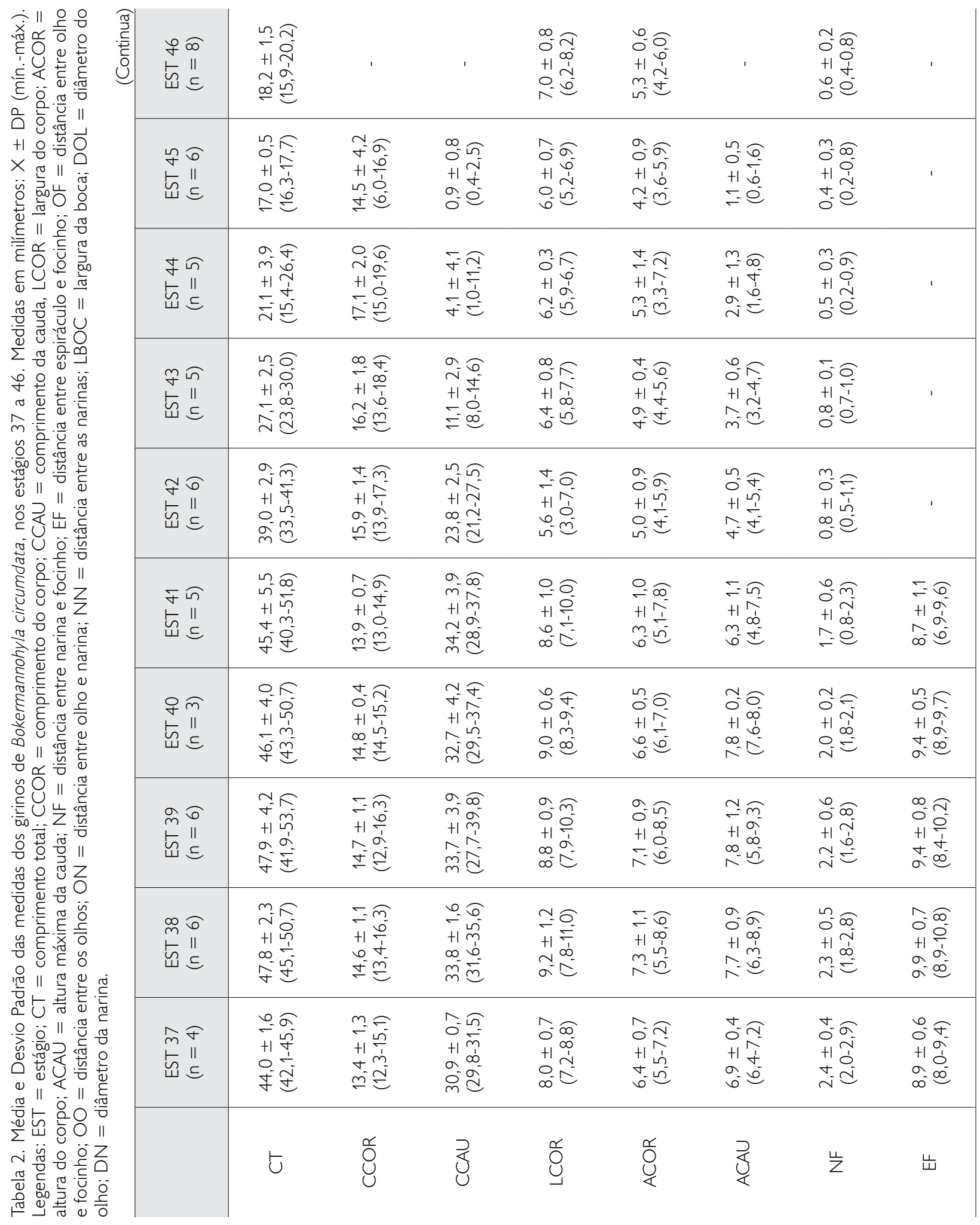




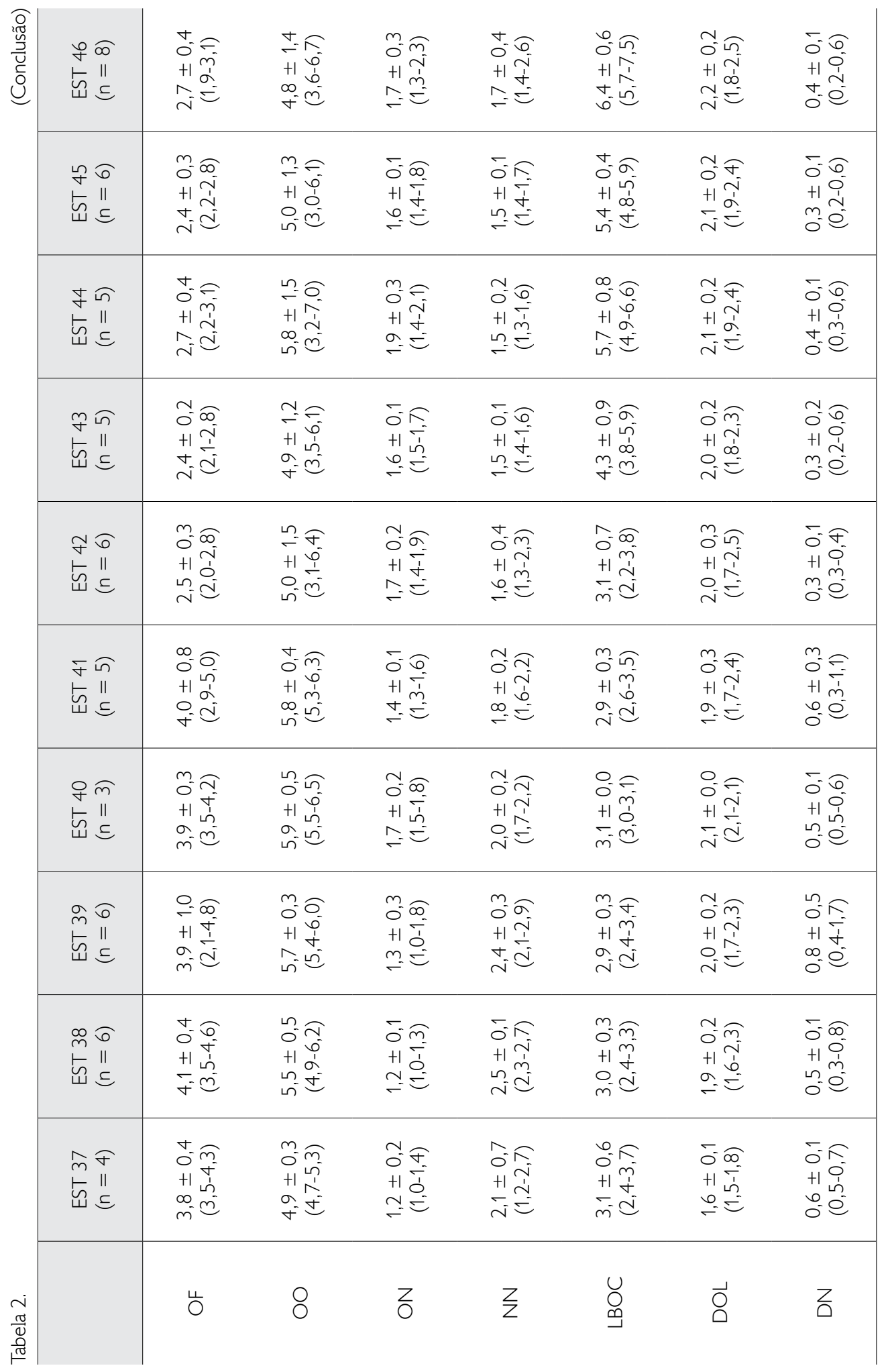


Tabela 3. Fórmulas dentárias encontradas por estágio no girino de Bokermannohyla circumdata em Teresópolis, com a proporção das fórmulas dentárias por estágio entre parênteses. Legenda: FD = fileiras despigmentadas.

\begin{tabular}{c|c|c|c|c|c}
\hline \multirow{2}{*}{ Estágio } & \multicolumn{5}{|c}{ Fórmulas dentárias } \\
\cline { 2 - 5 } & $2(2) / 3$ & $2(2) / 3(1)$ & $2(2) / 4$ & $2(2) / 4(1)$ & FD \\
\hline $25(n=20)$ & $2(0,10)$ & $17(0,85)$ & $1(0,05)$ & 0 & 0 \\
$26(n=9)$ & 0 & $3(0,33)$ & $1(0,11)$ & $5(0,56)$ & 0 \\
$27(n=6)$ & 0 & $4(0,67)$ & 0 & $2(0,33)$ & 0 \\
$28(n=4)$ & 0 & $2(0,67)$ & 0 & $1(0,33)$ & 1 \\
$29(n=2)$ & 0 & 0 & 0 & $2(1,00)$ & 0 \\
$31(n=4)$ & 0 & 0 & 0 & $2(1,00)$ & 2 \\
$32(n=2)$ & 0 & 0 & 0 & $2(1,00)$ & 0 \\
$34(n=1)$ & 0 & 0 & 0 & $1(1,00)$ & 0 \\
$35(n=3)$ & 0 & 0 & 0 & $3(1,00)$ & 0 \\
$36(n=5)$ & 0 & $1(0,25)$ & 0 & $3(0,75)$ & 1 \\
$37(n=4)$ & 0 & 0 & 0 & $3(1,00)$ & 1 \\
$38(n=3)$ & 0 & 0 & 0 & $1(1,00)$ & 2 \\
$39(n=5)$ & 0 & 0 & 0 & $2(1,00)$ & 3 \\
$40(n=3)$ & 0 & $1(1,00)$ & 0 & 0 & 2 \\
$41(n=5)$ & 0 & 0 & 0 & $2(1,00)$ & 3 \\
\hline
\end{tabular}

Teto bucal: área pré-coanal com crista de papilas de formato levemente irregular, com base larga, maior que seu ápice, podendo ter algumas pústulas entre as coanas; estas reniformes, largas, separadas e orientadas em ângulo de $45^{\circ}$ em relação ao plano transverso; menor distância entre as coanas aproximadamente quatro vezes menor que a largura da crista mediana; área pós-coanal podendo apresentar algumas pústulas; duas papilas situadas à frente da crista mediana, dispostas no mesmo plano transverso, largas e compridas, entre elas uma a duas papilas curtas e arredondadas, com algumas pústulas em volta; papila lateral da crista mediana complexa, com formato palmar, possuindo quatro projeções alongadas e finas de tamanho crescente, da parte anterior para a posterior da cavidade oral direcionadas para o centro, crista mediana quase tão larga quanto comprida, de formato triangular, com margem anterior serrilhada em toda a extensão; área do teto bucal delimitada por cerca de oito papilas de cada lado, digitiformes, afiladas, curtas, de superfície lisa e direcionadas para o centro; presença de papilas diminutas concentradas na base da arena, que se confundem com as pústulas; grande número de pústulas recobrindo uniformemente a superfície da arena; padrão de desenho formado pela disposição das papilas segue o da arena do assoalho.

Girino no estágio 26 difere do estágio 36 por possuir as papilas mais longas na arena do assoalho, nas bolsas bucais e na arena do teto e nas laterais. Foram observadas as seguintes variações, independente do estágio: número de papilas da crista da região pré-coanal podendo variar de uma a duas; papilas reduzidas da região pós-coanal podendo variar em número, mas sempre presente; crista mediana apresentando várias vezes uma separação, sendo seu lado direito maior do que o esquerdo, mas com o ápice pontiagudo; papilas das bolsas bucais diminutas em alguns exemplares. 

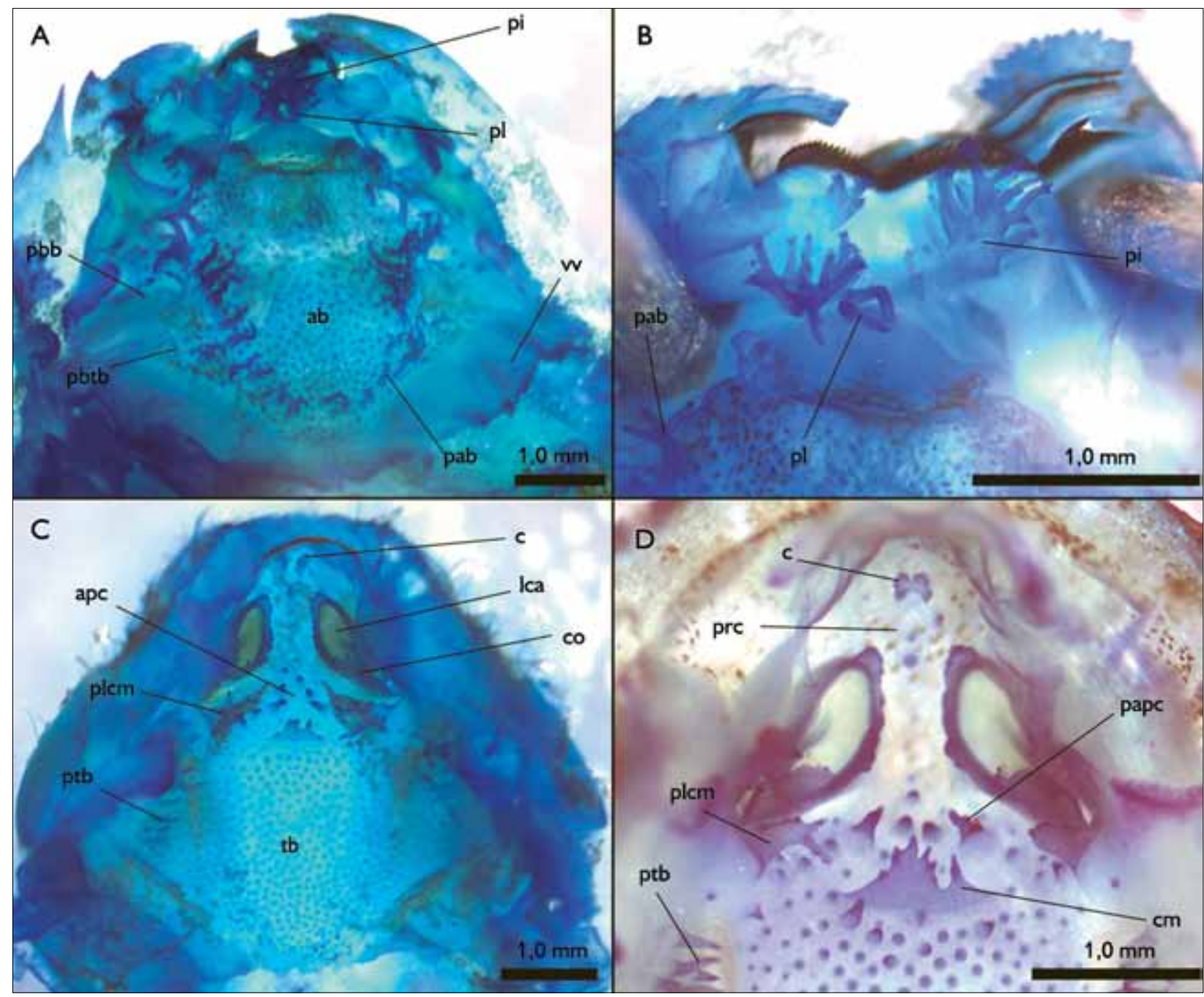

Figura 3. Morfologia oral interna do girino de Bokermannohyla circumdata: assoalho bucal (A, B) e teto bucal (C, D). Legendas: ab $=$ assoalho bucal; $\mathrm{apc}=$ área pós-coanal; $\mathrm{c}=$ crista de papilas na área pré-coanal; $\mathrm{cm}=$ crista mediana; $\mathrm{co}=\mathrm{coana}$; lca $=$ luz da coana; pab = papilas do assoalho bucal; papc = papilas da área pós-coanal; pbb = papilas da bolsa bucal; pbtb = papilas basais do teto bucal; pi = papilas infralabiais; $\mathrm{pl}=$ papilas linguais; plcm = papila lateral à crista mediana; prc = área pré-coanal; tb $=$ teto bucal; $p t b=$ papilas do teto bucal; vv = velum ventral. Figura 3B com alfinetes separando a região com as papilas infralabiais Estágios 36 (A, B, C) e 28 (D).

\section{VARIAÇÃO NA FÓRMULA DE DENTÍCULOS LABIAIS}

Dos 126 indivíduos estudados, 76 tiveram o número de fileiras de dentículos analisado, entre os estágios 25 e 41 (Tabela 3). Foi encontrada variação na fórmula de dentículos labiais [2(2)/3; 2(2)/3(1); 2(2)/4; 2(2)/4(1)], sendo que $5,4 \%$ apresentaram despigmentação, impossibilitando identificar a fórmula. Utilizando apenas a proporção dos girinos com fórmula dentária identificada por estágio, o Teste de Friedman demonstrou relação significativa entre o estágio de desenvolvimento e a fórmula de dentículos labiais encontrada $\left(n=15\right.$, grau de liberdade $=3, \chi^{2}=$ $22,91, p<0,00004)$, sugerindo que o desenvolvimento do girino influencia no número de fileiras.

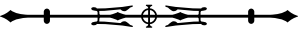




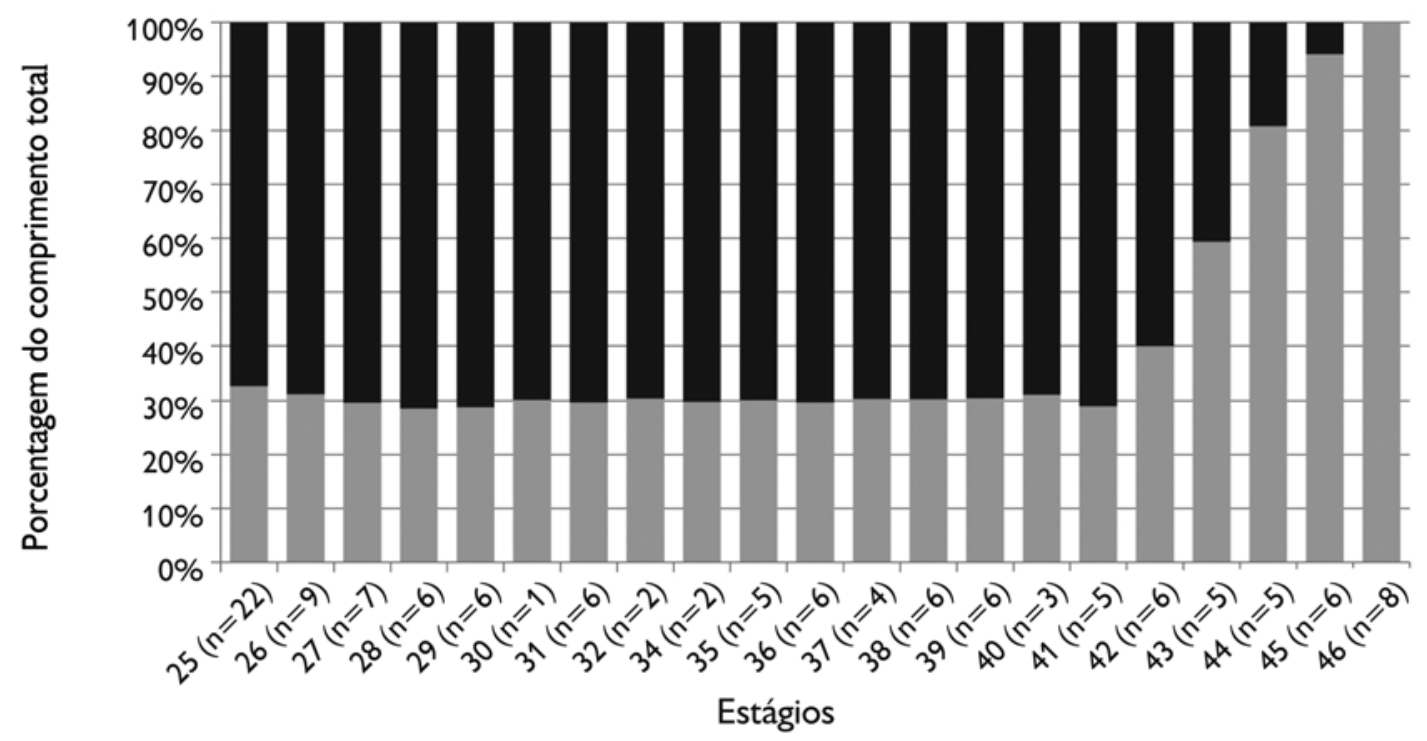

CCOR DCCAU

Figura 4. Ontogenia de Bokermannohyla circumdata: proporção do corpo (CCOR) e cauda (CCAU) em relação ao comprimento total.

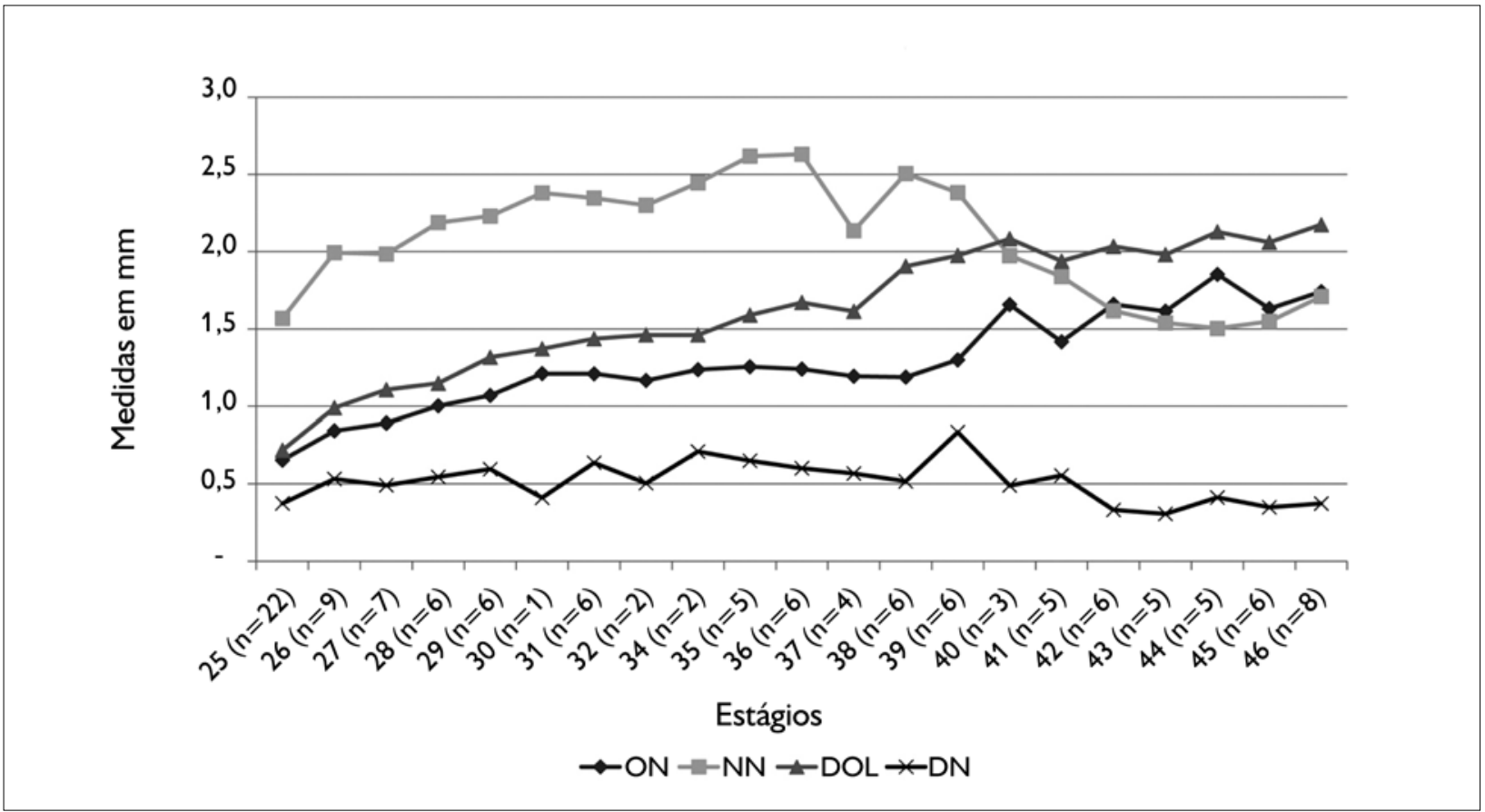

Figura 5. Ontogenia de Bokermannohyla circumdata: desenvolvimento das distâncias entre olho-narina (ON), internasal (NN), diâmetro do olho (DOL) e diâmetro da narina (DN).

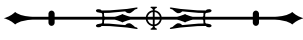




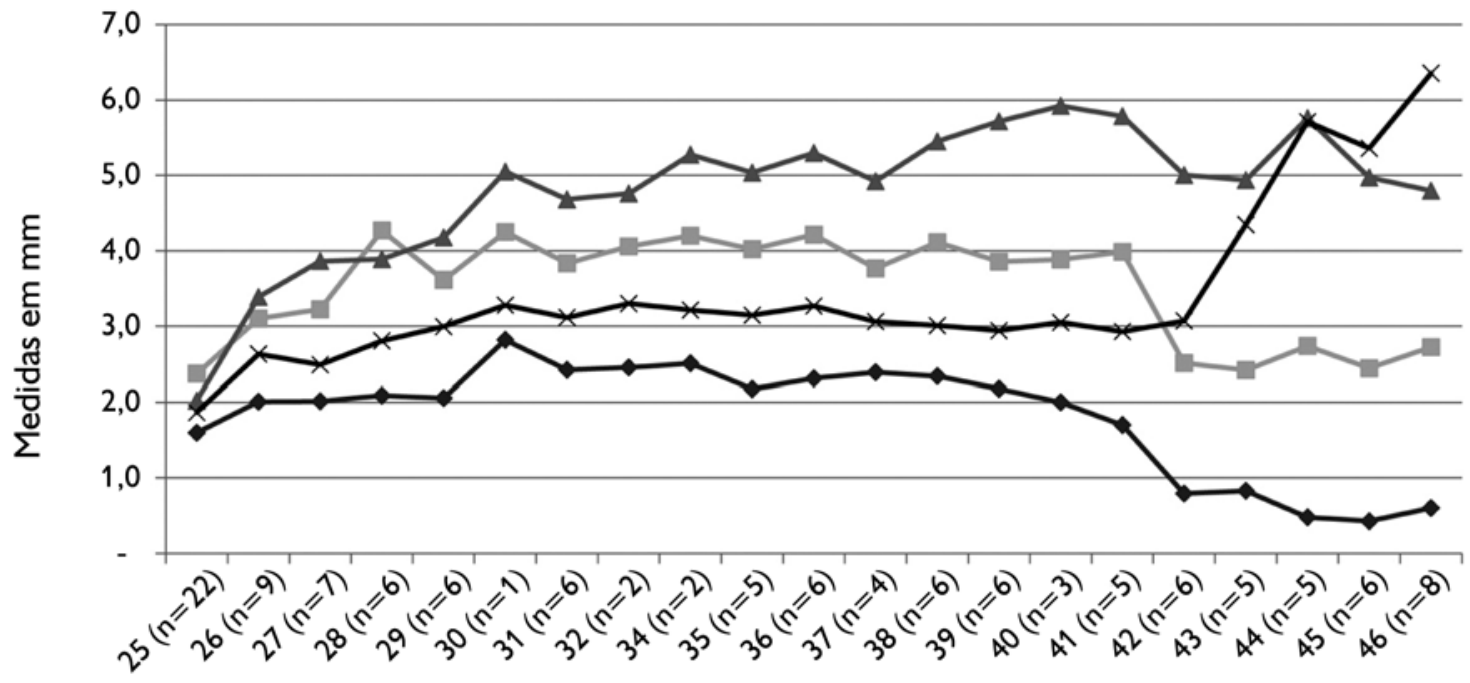

Estágios

$\rightarrow N F \rightarrow-O F \multimap O O *$ LB

Figura 6. Ontogenia de Bokermannohyla circumdata: desenvolvimento das distâncias entre narina-focinho (NF), olho-focinho (OF), interocular (OO) e largura da boca (LB).

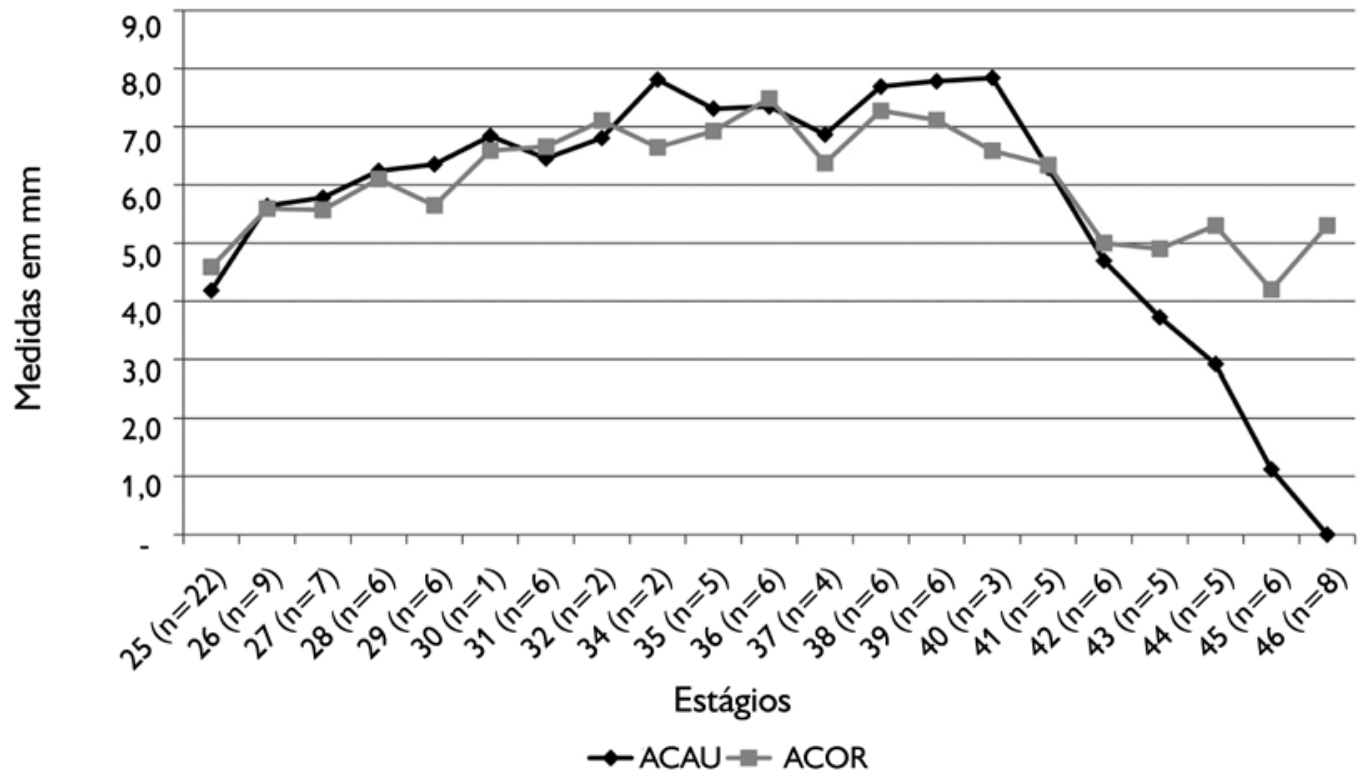

Figura 7. Ontogenia de Bokermannohyla circumdata: desenvolvimento das alturas da cauda (ACAU) e do corpo (ACOR).

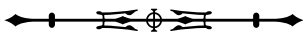




\section{COLORAÇÃO DO GIRINO}

Em vida, possui dorso marrom-escuro (Color 22, Burnt Umber) com pontuações pretas (Color 119, Sépia), cauda bege (Color 24, Buff) com máculas marrons (Color 33, Cinnamon Brown) ou formadas por pontuações pretas (Color 119, Sépia); nadadeira superior translúcida em cor bege (Color 26, Clay) com máculas marrons (Color 33, Cinnamon Brown), inferior mais clara (Color 38, Tawny) com máculas bege-escuro (Color 37, Antique Brown). Na cauda em vista lateral, há duas faixas marrom-escuro (Color 21, Fuscous) longitudinais ao longo da musculatura: uma superior à musculatura epiaxial por todo seu comprimento, interrompida ou não, outra entre as musculaturas epi- e hipoaxial até o terço médio da cauda. Em vista dorsal, há uma faixa mediana sob toda a nadadeira superior em cor bege-clara (Color 26, Clay), e as faixas das musculaturas epiaxial seguem paralelas lateralmente a esta. Sistema de linha lateral com pequenas pontuações claras (Color 92, Pale Horn). Ventre translúcido; olho preto (Color 119, Sépia) no círculo central, com uma linha de contorno dourado (Color 157, Sulfur Yellow) e preto com pigmentação dourada nessas mesmas cores no restante da circunferência (Figura 1D e 2B).

No preservativo, possui dorso marrom-escuro (Color 223, Raw Umber), cauda bege-escura (Color 223C, Sayal Brown) com máculas marrom-claro (Color 223B, Verona Brown); a nadadeira superior, a inferior e a parte superior do ventre passam a ter cor bege-escura (Color 123C, Sayal Brown) e perdem as máculas. Na cauda em vista lateral, as faixas ficam mais escuras (Color 223, Raw Brown). A faixa da cauda vista dorsalmente também escurece (Color 223C, Sayal Brown). O olho torna-se preto (Color 119, Sépia) com poucas máculas espaçadas em bege-claro (Color 92, Pale Horn) (Figuras 1A-1I; 2A). Os girinos no estágio 25 provenientes da desova $(n=5)$, logo após a eclosão, ainda não apresentavam a coloração característica da espécie, e sim coloração pálida com pouca pigmentação (Figura 2A, 25).

\section{COLORAÇÃO DO RECÉM-METAMORFOSEADO}

A coloração geral do recém-metamorfoseado pode mudar, assim como no adulto, de uma fase com cores claras para uma fase com cores escuras (Figura 2C-F).

Em vida, com a fase clara (Figura 2E), possui o dorso bege (Color 92, Pale Horn), com vários pontos marromescuros (Color 33, Cinnamon Brown); parte interna e externa da coxa, face ventral dos pés e mãos, assim como os dedos I, II e III em vista dorsal possuem cor laranjaclaro (Color 16, Chrome Orange). Ventre cinza (Color 44, Smoke Gray). Canto rostral marrom-claro (Color 136, Raw Sienna). A parte dorsal do tarso e pé (dedos IV e V) possui coloração bege-clara (Color 54, Cream).

No preservativo, fixado na fase clara (Figura 2A, 46), o dorso apresenta cor bege-escura (Color 223C, Sayal Brown) na parte superior e bege mais clara (Color 123D, Chamois) nas laterais, com vários pontos de cor marrom (Color 223A, Mars Brown); parte interna e externa da coxa, face ventral dos pés e mãos, assim como os dedos I, II e III de ambos em vista dorsal possuem cor bege mais clara que o dorso (Color 223D, Tawny Olive). $O$ ventre torna-se bege-claro transparente (Color 54, Cream Color). O canto rostral é marrom (Color 223A, Mars Brown). A parte dorsal do tarso e pé (dedos IV e V) é bege-clara (Color 223D, Tawny Olive).

Em vida, com a fase escura (Figura 2C-D), possui o dorso marrom-escuro (Color 219A, Natal Brown), com vários pontos pretos (Color 119, Sépia); parte interna e externa da coxa, face ventral dos pés e mãos, assim como os dedos I, Il e III em vista dorsal possuem cor laranja-escuro (Color 15, Flame Scarlet). Ventre cinza (Color 44, Smoke Gray). A linha da lateral da cabeça fica na mesma cor que o restante do corpo, assim como a parte dorsal do tarso e pé (dedos IV e V), marrom-escura (Color 219A, Natal Brown).

No preservativo, fixado na fase escura (Figura 2A, 45), o dorso apresenta cor marrom-escura (Color 121, Vandyke Brown) na parte superior e marrom mais clara (Color 121A, Prout's Brown) nas laterais, com vários pontos pretos (Color 219, Sépia); parte interna e externa da coxa, face ventral dos 
pés e mãos, assim como os dedos I, II e III de ambos em vista dorsal, além da parte dorsal do tarso e pé, possuem cor bege, mais clara que o dorso (Color 132, Burnt Sienna). 0 ventre torna-se bege-claro transparente (Color 219D, Beige). O canto rostral é marrom (Color 121, Vandyke Brown).

\section{DISCUSSÃO}

$A$ desova de $B$. circumdata é muito similar às de $B$. napolii (Carvalho et al., 2012) e de B. luctuosa (Pombal Jr. \& Haddad, 1993), tanto no tipo de ambiente quanto no aspecto geral, porém possui maior número de ovos, sendo 1.176 ovos com diâmetro médio de 8,8 $\pm 0,7(7,65-10,20) \mathrm{mm}(\mathrm{n}=$ 10) em vida e $6,3 \pm 1,2(4,90-8,25) \mathrm{mm}(\mathrm{n}=10)$ fixados. Bokermannohyla napolli possui $637 \pm 176(373-742)(n=$ 4) ovos por desova, com diâmetro médio de 4,4 \pm 0,6 $(3,8-5,4) \mathrm{mm}$, e B. luctuosa possui ovos de diâmetro médio de 4,95 $\pm 0,26 \mathrm{~mm}(\mathrm{n}=8)$, considerando-se a cápsula gelatinosa. Esse tipo de desova também é semelhante ao de B. ibitipoca (Magalhães et al., 2012).

As diferenças entre o girino de B. sazimai e $B$. circumdata estão no fato de o primeiro ser maior (CT 60,0 mm no estágio 27); possuir fileira simples de papilas marginais na boca; ter cauda até $1 / 3$ mais alta que o corpo e bastante pigmentada com manchas irregulares e escuras ao longo de toda a porção membranosa; possuir uma faixa escura mediana longitudinal no primeiro terço da musculatura caudal, que se mistura às manchas das nadadeiras no terço posterior. Em B. circumdata, o girino, no mesmo estágio, é quase duas vezes menor (CT 35,0 \pm 3,9, 28,4-39,5 mm, $\mathrm{n}=7$ ); a fileira de papilas é dupla, podendo ser simples apenas na porção anterior; a altura da cauda é pouco maior do que altura do corpo; as manchas na nadadeira são claras e a faixa não se une às manchas da nadadeira caudal.

Os girinos de $B$. capra descritos por Mercês et al. (2012) nos estágios 34-37 ( $n=6$ ), quando comparados aos girinos de $B$. circumdata nos mesmos estágios, possuem diferenças biométricas com diâmetro da narina e distância interorbital menores; proporcionalmente, a distância interocular em relação à largura do corpo $(0,32 \pm 0,01)$ é menor, assim como a largura da boca pela largura do corpo é maior $(0,44 \pm 0,02)$. Já em $B$. circumdata $(n=17)$, esses valores são 0,6 \pm 0,05 e 0,37 $\pm 0,04$ respectivamente. A fórmula de dentículos labiais 2(2)/4(1) é a mesma encontrada com maior frequência em $B$. circumdata.

Costa et al. (2010) descreveram o girino de B. gouveai baseados em oito exemplares entre os estágios 30 e 37 . Estes se diferenciam de $B$. circumdata por possuírem fórmula de dentículos labiais 2(2)/3 sem variação e presença de papilas submarginais no disco oral e pelo corpo maiores, porém com diâmetro da narina e distância interorbital menores. Proporcionalmente, em B. gouveai o comprimento do corpo é maior (CCOR/CT 33,3\%), as narinas são mais afastadas (NN/OO 71,4\%) e equidistantes entre olho e focinho (ON/ OF 50\%), sendo em B. circumdata nos mesmos estágios $(n=25)$ CCOR/CT 30,4 \pm 1,6\%, NN/OO 48,7 \pm 6,0\% e ON/OF 30,8 \pm 5,3\%.

O girino de B. ibitipoca descrito por Magalhães et al. (2012) possui coloração muito similar, porém é maior, com o comprimento do corpo ocupando pouco mais de 1/3 do comprimento total, mais estreito; fórmula de dentículos labiais 2(2)/4(1); distância interocular menor; diâmetro do olho maior; olhos e narinas mais afastados do focinho. Proporcionalmente, no estágio $36(n=8)$, utilizando as médias, NN/OO é $72 \%$; já em B. circumdata, no mesmo estágio ( $n=6$ ), essa proporção é $49 \pm 4,6 \%$.

O girino de B. feioi descrito por Napoli \& Caramaschi (2004) no estágio 36 ( $n=2$ ) distingue-se de $B$. circumdata pelo comprimento total maior (CT 52,2-54,6 mm) e corpo em formato arredondado, em vista dorsal e lateral; distância do espiráculo ao focinho ( $E F$ 6,6-7,0 mm), sendo distância do espiráculo ao focinho 33,5-35,0\% do comprimento do corpo; cauda proporcionalmente menor, com comprimento 61,8-63,3\% do comprimento total; coloração marmórea, predominantemente escura, com nuances de marrom-claro a escuro; o ventre não é translúcido, mas de coloração marrom-avermelhada. Em B. circumdata, no estágio $36(n=6)$, o comprimento total é menor (CT 46,8 \pm 4,8 mm); distância entre espiráculo 
e focinho é maior (EF 9,1 \pm 0,5 mm), sendo 56,6-68,5\% do comprimento do corpo; comprimento da cauda 70,6$74,6 \%$ do comprimento total, com a coloração mais clara e o ventre translúcido. No recém-metamorfoseado (RM) de B. feioi, já é possível distinguir a linha dorso-lateral característica da espécie ausente no RM de $B$. circumdata.

$O$ girino de $B$. hylax descrito por Bertoluci et al. (2003) diferencia-se daquele de $B$. circumdata, segundo os autores, pelo aspecto listrado da cauda em vista dorsal e espiráculo não pigmentado. Também é possível diferenciá-los, com base neste trabalho, pelo disco oral sem interrupção na margem anterior, com borda de papilas duplas ou não, sem borda na margem inferior, fórmula oral predominante 2(2)/4-4(1) mesmo no estágio 25, e pelo comprimento total (CT), em geral menor ( $16,4 \mathrm{~mm})$ no estágio 25 , maior $(38,0 \mathrm{~mm})$ no estágio 29, apresentando $36,9 \mathrm{~mm}$ no estágio 38 , maior estágio utilizado na descrição. Neste trabalho, nos mesmos estágios, o CT menor foi de 16,4 mm no estágio 25, 42,7 mm no estágio 29 e o maior CT (50,7 mm) no estágio 38. Proporcionalmente, no estágio $36(n=4)$, a narina de $B$. hylax é mais próxima ao focinho, sendo $7,8 \%$ da distância do comprimento do corpo, enquanto que, em B. circumdata, no mesmo estágio $(n=7)$, essa proporção é de 16,6\%. Comparando a coloração descrita neste estudo e a fotografia publicada em Bertoluci (2002), parece não haver diferença no padrão de coloração, inclusive o espiráculo de $B$. circumdata possui a extremidade não pigmentada, assim como B. hylax.

O girino de Bokermannohyla nanuzae descrito por Bokermann \& Sazima (1973) difere daquele de B. circumdata por apresentar tamanho maior, $65 \mathrm{~mm}$ no estágio 33/34; nadadeiras altas; espiráculo colado; bico córneo não muito forte, na parte superior serrilhado apenas nas laterais; coloração preta com tênue castanho na parte musculosa da cauda; ventre corado; ocupa ambiente lótico. Em B. circumdata, no estágio 34 ( $n=2)$, o comprimento total é menor, 41,3 a 49,0 mm $(n=2)$; nadadeiras baixas, espiráculo solto, bico córneo serrilhado sem interrupção e coloração mais clara com ventre translúcido, ocupando ambiente lêntico na maioria das vezes. O tamanho do recém-metamorfoseado de B. nanuzae é de 22,0 a 25,0 mm, enquanto que em $B$. circumdata é menor (15,9-20,2 mm) ( $\mathrm{n}=8)$; a coloração é similar, diferindo, porém, na face interna das patas, que é salmão-claro em $B$. nanuzae, conforme fotografia no livro de Eterovick \& Sazima (2004). Em B. circumdata, essa coloração é laranja, podendo variar de intensidade. A morfologia oral interna de $B$. nanuzae é descrita por D'Heursel \& Haddad (2007) e se diferencia pelo fato de esta não possuir papilas transversais e papilas das bolsas bucais, presentes em $B$. circumdata.

Peixoto (1981), ao descrever o girino de B. carvalhoi do Parque Nacional da Serra dos Órgãos, compara-o com o girino de B. circumdata por ocorrerem nos mesmos riachos, fazendo assim uma breve descrição. $O$ autor do referido trabalho indicou como principais diferenças o fato de $B$. carvalhoi possuir corpo robusto e cauda mais alta, proporcionalmente mais curta em relação ao corpo, coloração do dorso uniformemente pardo-enegrecida ou cinza-claro, extremidade da cauda arredondada, fórmula de dentículos labiais 2(2)/5(1). Esse mesmo autor fornece as seguintes medidas para $B$. carvalhoi no estágio $31(n=1)$ : CT $47 \mathrm{~mm}$, CCOR $17 \mathrm{~mm}$, ACOR 9 mm, LCOR $11 \mathrm{~mm}$, OF $3 \mathrm{~mm}$, DOL $2 \mathrm{~mm}$; enquanto que $B$. circumdata, no estágio 36 , é descrito com fórmula 2(2)/3(1), padrão geral de colorido mais claro e aspecto menos robusto do corpo e musculatura caudal. Utilizando os dados aqui descritos, observamos que o girino de $B$. circumdata no estágio 31 ( $n=6$ ) é, em média, menor 46,8 4 4,8 (42,2$56,0 \mathrm{~mm}$ ), podendo alcançar tamanho maior do que o descrito para $B$. carvalhoi, entretanto os valores máximos registrados para CCOR, ACOR, LCOR e DOL são menores (Tabela 1), devido ao fato de o corpo ser menor e a cauda proporcionalmente maior. Também diferem pelo ventre translúcido, padrão de coloração com duas faixas longitudinais e a fórmula de dentículos labiais com a seguinte variação: [2(2)/3; 2(2)/3(1); 2(2)/4; 2(2)/4(1)]. 
Pombal Jr. \& Haddad (1993) descreveram o girino de B. luctuosa baseados em exemplares no estágio 25 , obtidos a partir de uma desova, criados por pouco tempo (Pombal Jr. \& Haddad, 2013, comunicação pessoal). Sua morfologia, baseada no desenho e dados do referido trabalho, é muito similar à do girino de $B$. circumdata com poucas horas de vida. Bokermannohyla luctuosa difere pelo tamanho um pouco menor (CT 14,9 mm e CCOR 5,0 mm), enquanto que os cinco girinos provenientes da desova coletada por nós apresentaram CT 16,85 \pm 1,10 (15,69-18,55) mm e CCOR 5,26 $\pm 0,30(4,94-5,72) \mathrm{mm}$. Nos girinos de $B$. circumdata, a coloração, assim como os demais aspectos da morfologia que os caracterizam, só se tornarão aparentes com algum tempo de vida, sendo difícil diferenciá-los entre essas espécies nesse estágio. Porém, baseado no trabalho de D'Heursel \& Haddad (2007), que descreveram a morfologia oral interna de B. luctuosa, é possível distinguilos: $B$. circumdata difere por apresentar duas papilas linguais, enquanto $B$. luctuosa possui três, e ainda pelo fato de a área pré-nasal apresentar papilas transversais e papilas das bolsas bucais, enquanto que $B$. luctuosa não as possui.

Em B. circumdata, no decorrer do desenvolvimento (estágios 26 e 36), o número de papilas da arena do assoalho aumenta, unindo, na parte posterior, as duas fileiras que contornam a região, enquanto que as papilas infralabiais e linguais aumentam de tamanho. Não foi observada nenhuma estrutura presente no estágio 26 que não estivesse presente no estágio 36. Foi observada pequena variação na forma de algumas estruturas: papila da área pré-coanal com formato bífido mais acentuado no estágio 26, crista mediana com entalhe profundo no lado esquerdo do animal, quase dividida em duas partes, em alguns indivíduos de ambos os estágios. Com o decorrer do desenvolvimento, essas estruturas deixam de existir, pois o recém-metamorfoseado possui a estrutura oral similar à dos adultos.

A relação significativa encontrada entre o estágio de desenvolvimento e a fórmula de dentículos labiais indica que ocorre mudança na morfologia oral externa no decorrer do desenvolvimento. $O$ surgimento de mais uma fileira de dentículos pode ser considerado um caráter ontogênico. A fórmula de dentículos labiais é um caráter importante na identificação taxonômica de girinos e existem poucos estudos relacionando a variação desta com os diferentes estágios de desenvolvimento (Orrico et al., 2007 para Hypsiboas latistriatus (Caramaschi \& Cruz, 2004); Bertoluci et al., 2003 para B. hylax; Carnaval \& Peixoto, 2004 para H. freicanecae (Carnaval \& Peixoto, 2004); Lötters et al., 1999 para H. pulchellus (Duméril \& Bibron, 1841); Duellman et al., 1997 para H. andinus Faivovich, Haddad, Garcia, Frost, Campbell, \& Wheeler, 2005; Gallardo, 1962 para H. pulchellus), o que reforça a importância de se analisar um maior número de indivíduos em diferentes estágios de desenvolvimento.

Os estágios 42 e 43 da tabela de Gosner (1960) ocorrem diferentemente em $B$. circumdata: antes de perder o aparato bucal, a linha da boca ultrapassa a linha da narina, o que não ocorre na referida tabela. No presente trabalho, foi considerado como a principal diferença entre os estágios 42 e 43 o fato de o estágio 42 ainda apresentar sistema de linha lateral no canto rostral e o estágio 43 não possuir sistema de linha lateral no canto rostral e a membrana da nadadeira caudal começar a ser absorvida.

A coloração do recém-metamorfoseado, assim como nos adultos, muda de tons bege muito claros ao marromescuro em poucos minutos, dependendo da intensidade de luz e do ambiente, porém sempre mantendo as pontuações negras no dorso e o alaranjado nos membros.

As descrições dos girinos do grupo de $B$. circumdata são baseadas em poucos exemplares, em alguns casos em um indivíduo ou em girinos no estágio inicial. As espécies desse grupo possuem adultos com coloração e padrão muito similares, sendo importante um estudo mais aprofundado sobre seus girinos.

A análise dos diferentes estágios permitiu encontrar variações que ocorrem no decorrer do desenvolvimento. Por essa razão, trabalhos que descrevem diferentes estágios fornecem mais dados e possibilitam uma identificação mais segura. 


\section{AGRADECIMENTOS}

Agradecemos aos pesquisadores: J. P. Pombal Jr. e C. F. B. Haddad, pelas informações sobre a desova e os girinos de B. luctuosa; a F. C. B. Rosa, V. G. D. Orrico, L. T. Sabagh, P. A. Valadares, L. A. Cordioli e P. H. S. Dias, pela ajuda no campo e no laboratório; a M. G. Mocellin, pela assistência nas análises estatísticas; a C. Luna-Dias, pela foto do girino em vida; ao editor M. Hoogmoed e aos dois revisores anônimos pelas relevantes sugestões; à Universidade Federal do Estado do Rio de Janeiro, pelo suporte, transporte e utilização do Laboratório de Microscopia e Análise de Imagens; a C. Cronemberger e ao Parque Nacional da Serra dos Órgãos, pela permissão de coleta e suporte em campo; ao Conselho Nacional de Desenvolvimento Científico e Tecnológico (CNPQ), pela bolsa de iniciação científica e pelas autorizações de coleta n 02001,007165/01-18, 02022,002840/05-05 IBAMA e $n^{\circ} 22812$ SISBIO.

\section{REFERÊNCIAS}

BERTOLUCI, J., 2002. Diel activity of the tadpoles of Hyla hylax (Anura: Hylidae) at Boracéia, Southeastern Brazil. Phyllomedusa 1(1): 41-43.

BERTOLUCI, J., V. XAVIER \& J. CASSIMIRO, 2003. Description of the tadpole of Hyla hylax (Anura, Hylidae) with notes on its ecology. Amphibia-Reptilia 24(4): 509-514.

BOKERMANN, W. C. A., 1966. Lista anotada das localidades tipo de anfíbios brasileiros: 1-183. Serviço de Documentação, São Paulo.

BOKERMANN, W. C. A. \& I. SAZIMA, 1973. Anfíbios da Serra do Cipó, Minas Gerais, Brazil. 1: Duas espécies novas de Hyla (Anura, Hylidae). Revista Brasileira de Biologia 33(4): 457-472.

CARDOSO, A. J. \& G. V. ANDRADE, 1982. Nova espécie de Hyla do Parque Nacional da Serra da Canastra (Anura, Hylidae). Revista Brasileira de Biologia 42(3): 589-593.

CARNAVAL, A. C. O. Q. \& O. L. PEIXOTO, 2004. A new species of Hyla from northeastern Brazil (Amphibia, Anura, Hylidae). Herpetologica 60(3): 387-395.

CARVALHO, T. R., A. A. GIARETTA \& L. MAGRINI, 2012. A new species of the Bokermannohyla circumdata group (Anura: Hylidae) from southeastern Brazil, with bioacoustic data on seven species of the genus. Zootaxa 3321: 37-55.
CARVALHO-E-SILVA, S. P. \&A. M. P. T. CARVALHO-E-SILVA, 1994. Descrição das larvas de Ololygon albicans e de Ololygon trapicheiroi com considerações sobre sua biologia (Amphibia, Anura, Hylidae). Revista Brasileira de Biologia 54: 55-62.

COSTA, P. N., A. C. C. LOURENÇO, P. ALMEIDA-SANTOS \& M. V. SLUYS, 2010. Tadpole of the hylid frog Bokermannohyla gouveai (Peixoto \& Cruz, 1992). Zootaxa 2418: 61-64.

D'HEURSEL, A. \& C. F. B. HADDAD, 2007. Anatomy of the oral cavity of hylid larvae from the genera Aplastodiscus, Bokermannohyla, and Hypsiboas (Amphibia, Anura): description and systematic implications. Journal of Herpetology 41(3): 458-468.

DUELLMAN, W. E., I. DE LA RIVA \& E. R. WILD, 1997. Frogs of the Hyla armata and Hyla pulchella groups in the Andes of South America, with definitions and analyses of phylogenetic relationships of Andean groups of Hyla. Scientific Papers 3: 1-41.

ETEROVICK, P. C. \& I. SAZIMA, 2004. Anfíbios da Serra do Cipó, Minas Gerais, Brasil: 1-152. Ed. PUC Minas, Belo Horizonte.

FAIVOVICH, J., C. F. B. HADDAD, P. C. A. GARCIA, D. R. FROST, J. A. CAMPBELL \&W. C. WHEELER, 2005. Systematic review of the frog family Hylidae, with special reference to Hylinae: phylogenetic analysis and taxonomic revision. Bulletin of the American Museum of Natural History 294: 1-240.

FROST, D. R., 2011. Amphibian species of the World 5.6, an Online Reference. American Museum of Natural History, New York. Disponível em: <http://research.amnh.org/herpetology/ amphibia/>. Acesso em: 13 julho 2012.

GALLARDO, J. M., 1962. Observaciones biológicas sobre Hyla raddiana de la Provincia de Buenos Aires. Ciencia e Investigación 17(3): 61-69.

GOSNER, K. L., 1960. A simplified table for staging anuran embryos and larvae with notes on identification. Herpetologica 16(3): 183-190.

HEYER, W. R., 1985. New species of frogs from Boracéia, São Paulo, Brazil. Proceedings of the Biological Society of Washington 98(3): 657-671.

LÖTTERS, S., J. KÖHLER \& S. REICHLE, 1999. Description of the tadpole of the Andean treefrog Hyla marianitae (Amphibia: Anura: Hylidae). Folia Zoologica 48(1): 49-53.

MAGALHÃES, F. M., M. O. NEVES, E. M. FONSECA \& R. M. H. CARVALHO, 2012. The tadpole of Bokermannohyla ibitipoca (Caramaschi \& Feio, 1990) (Anura, Hylidae). Zootaxa 3415: 58-62.

MCDIARMID, R. W. \& R. ALTIG, 1999. Tadpoles: the biology of anuran larvae: XIV-444. University of Chicago Press, Chicago/London.

MERCÊS, E. A., A. S. PROTÁZIO \& F. A. JUNCÁ, 2012. The tadpole of Bokermannohyla capra Napoli \& Pimenta 2009 (Anura, Hylidae). Zootaxa 3167: 66-68. 
MIRANDA, N. E. O. \& A. FERREIRA, 2009. Morfologia oral interna de larvas dos gêneros Eupemphix, Physalaemus e Leptodactylus (Amphibia: Anura). Biota Neotropica 9(2): 165-176.

NAPOLI, M. F., 2005. A new species allied to Hyla circumdata (Anura: Hylidae) from Serra da Mantiqueira, southeastern Brazil. Herpetologica 61(1): 63-69.

NAPOLI, M. F. \& U. CARAMASCHI, 2004. Two new species of the Hyla circumdata group from Serra do Mar and Serra da Mantiqueira, southeastern Brazil, with description of the advertisement call of Hyla ibitipoca (Anura, Hylidae). Copeia 3: 534-545.

NAPOLI, M. F. \& F. A. JUNCÁ, 2006. A new species of the Bokermannohyla circumdata group (Amphibia: Anura: Hylidae) from Chapada Diamantina, State of Bahia, Brazil. Zootaxa 1244: 57-68.

NAPOLI, M. F. \& B. V. S. PIMENTA, 2009. A new species of the Bokermannohyla circumdata Group (Anura: Hylidae) from the coastal forests of Bahia, Northeastern Brazil. Copeia 4: 674-683.

ORRICO, V. G. D., M. M. MONGIN \& A. M. P. T. CARVALHOE-SILVA, 2007. The tadpole of Hypsiboas latistriatus (Caramaschi \& Cruz, 2004), a species of the Hypsiboas polytaenius (Cope, 1870) clade (Amphibia, Anura, Hylidae). Zootaxa 1531: 25-37.
PEIXOTO, O. L., 1981. Nova espécie de Hyla da Serra dos Órgãos, Estado do Rio de Janeiro, Brasil (Amphibia: Anura: Hylidae). Revista Brasileira de Biologia 41(3): 515-520.

POMBAL JR., J. P. \& C. F. B. HADDAD, 1993. Hyla luctuosa, a new treefrog from Southeastern Brazil (Amphibia: Hylidae). Herpetologica 49(1): 16-21.

POMBAL JR., J. P. \& C. F. B. HADDAD, 2007. Estratégias e modos reprodutivos em anuros. In: L. B. NASCIMENTO \& M. E. OLIVEIRA (Eds.): Herpetologia no Brasil II: 101-116. Sociedade Brasileira de Herpetologia, Belo Horizonte.

SMITHE, F. B., 1975. Naturalist's color guide. American Museum of Natural History, New York.

WASSERSUG, R. J., 1976. Oral morphology of anuran larvae: terminology and general description. Occasional Papers of the Museum of Natural History 48: 1-23.

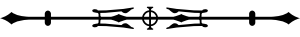

